\title{
Ethnicity, equity and quality: lessons from New Zealand (Nga mātawaka, nga āhua tika me nga painga: nga ākoranga no Aotearoa)
}

K M McPherson, M Harwood, H K McNaughton

\section{Shorter life expectancy and poorer outcomes associated with ethnicity are important issues for many countries. Some approaches to this problem in New Zealand are described.}

ife expectancy for indigenous people in colonised countries is shorter than Lit should be. In New Zealand, Māori die on average 10 years younger than people of Anglo-European descent. ${ }^{1}$ The usual suspects of poverty and poor socioeconomic opportunities contribute to inequity, but failures in service organisation and delivery are part of the picture. New Zealand is not the only colonised nation where higher rates of illness and premature mortality exist, but it is a country making concerted efforts to address the disparity.

The starting point in identifying inequality in health outcomes is ensuring accuracy of data. New Zealand is a diverse country; the 2001 census indicates that $14.1 \%$ of the population are Māori, $6.2 \%$ are Pacific people, and 6.4\% are Asian. ${ }^{2}$ Each of these groups is actually growing at a faster rate than pakeha (the white descendants of colonial settlers). However, until recently, documentation of ethnic origin in relation to health was not routinely collected. Even when ethnicity was recorded, it tended to be based on health workers' assessment of the appearance of the service user. Addressing health needs and planning appropriate levels of service clearly requires a more accurate and sensible approach. Self-identification of ethnicity is now established as "best practice" in New Zealand ${ }^{1}$ and, as a result, knowledge about health and the incidence and prevalence of certain conditions is improving.

A second step in enhancing responsiveness to cultural needs of patients is "cultural safety" introduced by Irihapeti Ramsden. ${ }^{3}$ Cultural safety goes further than learning factual information regarding dietary or religious needs of different ethnic groups. Rather, it means engaging with the sociopolitical context of beliefs about whanau (family) and of what is tapu (forbidden) in a range of healthcare practice, from washing someone through to physical examination or handling of biological specimens. It is increasingly understood that failure to take such things into consideration may well lead to interventions that fail in the short term and that build suspicion in the longer term as people lose their trust in healthcare providers. While cultural safety began as a movement within nursing, it is now being introduced within the other undergraduate curricula and professional development programmes.

Difficulties in accessing services have been identified for Māori and other ethnic groups in New Zealand. ${ }^{1}$ Resultwell contribute to the significantly worse outcomes found in patients with stroke, cancer, cardiovascular disease, diabetes, and mental illness. ${ }^{4-6}$ While services that use the principles of cultural safety can reduce barriers and encourage access, a number of culturally specific services have been successfully introduced. Among developments are GP services based within marae (local meeting houses), specialist outreach clinics for young people with mental health problems, and culturally specific health education programmes. ${ }^{1}$ Making decisions about where and when "culturally specific services" versus "culturally safe generic services" are most appropriate is difficult and complex. It is likely that each is required if high quality services are to be provided across the country.

Developing appropriate and responsive services requires dialogue and partnership between health service ant delays in initiating treatment may

organisers and community leaders. Partnership is a core component of the Treaty of Waitangi, the original agreement intended to protect the interests of both the original inhabitants and the incomers. The Treaty has not always been honoured by the New Zealand government or pakeha, and examples of institutional and personal racism are well documented. ${ }^{7}$ Over the last few decades the responsibilities of leadership have been challenged and many steps taken towards redressing the lack demonstrated throughout the 19th and 20th centuries. Experience from other countries suggests that, without the Treaty, New Zealand may well not have tackled much of the implicit and explicit discriminatory practice. Things are by no means perfect and, without continued effort, those improvements made so far may well be transitory. However, healthcare policy, clinical practice and research processes are now all influenced by the Treaty, and attention to the impact of ethnicity on health is growing.

The final issue highlighted here concerns how service effectiveness is evaluated. Most measures of process and outcome are based largely on Eurocentric or US perspectives. ${ }^{8}$ While there is a place for such approaches, they may well fail to address issues which matter most to people of different ethnic origin. A recent model which explicitly addresses a Māori perspective of health and wellbeing is the Whare Tapa Wha model developed by Durie, visualised as a "four sided house" where each construct is required for health (table 1). ${ }^{9}$ Durie suggests that the link between these four components is fundamental: "A person's synergy relies on these foundations being secure. Move one of these, however slightly, and the person may become unwell."

Although expert derived, this model is quite different from many others used in health care in being very definitely owned by the community. It makes the interconnectedness between different aspects of life and wellbeing explicit, has been the basis of new services, and underpins an outcome measure now used in mental health. ${ }^{10}$

Life expectancy and poorer outcomes in association with ethnicity remain important issues for many countries, including New Zealand. National and

\begin{tabular}{llll|}
\hline Table 1 & Whare Tapa Wha model & \\
\hline $\begin{array}{l}\text { Taha Wairua } \\
\text { (Spiritual) }\end{array}$ & $\begin{array}{l}\text { Taha Hinengaro } \\
\text { (Mind) }\end{array}$ & $\begin{array}{l}\text { Taha Tinana } \\
\text { (Physical) }\end{array}$ & $\begin{array}{l}\text { Taha Whanau } \\
\text { (Extended family) }\end{array}$ \\
\hline $\begin{array}{l}\text { Capacity for faith and } \\
\text { wider communion }\end{array}$ & $\begin{array}{l}\text { Capacity to communicate, } \\
\text { think and feel }\end{array}$ & $\begin{array}{l}\text { Capacity for physical } \\
\text { growth and development to care, and to share }\end{array}$ & $\begin{array}{l}\text { Capacity to belong, } \\
\text { ghel to }\end{array}$ \\
\hline
\end{tabular}


local developments such as those described here are making a difference, but ongoing and expanding effort is required if significant improvements in health are to occur.

Qual Saf Health Care 2003;12:237-238

\section{Authors' affiliations}

K M McPherson, $M$ Harwood, Wellington School of Medicine and Health Sciences, New Zealand

K M McPherson, School of Health Professions and Rehabilitation Sciences, University of Southampton, UK

H K McNaughton, Capital Coast Health, Wellington, Medical Research Institute of $\mathrm{New}$ Zealand
Correspondence to: Dr K McPherson, Reader in Rehabilitation, School of Health Professions and Rehabilitation Sciences, University of Southampton, Southampton SO17 1BJ, UK; k.mcpherson@soton.ac.uk

\section{REFERENCES}

1 Ministry of Health, New Zealand. Reducing inequalities in health. Wellington: Ministry of Health, 2002.

2 Statistics New Zealand. 2001 census of population and dwellings. www.stats.govt.nz/ census 2003 (accessed 19 May 2003).

3 Ramsden I. Cultural safety in nursing education in Aotearoa (New Zealand. Nursing Praxis in New Zealand 2003:8:4-10.

4 McNaughton $\mathbf{H}$, Weatherall M, McPherson $\mathrm{K}$, et al. The comparability of community outcomes for European and non-European survivors of stroke in New Zealand. NZ Med J 2002;115:98-100.
5 Sporle A, Pearce N, Davis P. Social class mortality differences in Maori and non-Maori men aged 15-64 during the last two decades. NZ Med J 2003;115:127-31.

6 Brinded PM, Simpson Al, Laidlaw TM, et al. Prevalence of psychiatric disorders in New Zealand prisons: a national study. Aust NZ J Psychiatry 2001;35:166-173.

7 Reid P, Robson B, Jones C. Disparities in health; common myths and uncommon truths. Pacific Health Dialogue 2000;7:38-48.

8 McPherson KM, Brander PM, McNaughton $\mathrm{H}$, et al. Living with arthritis: what is important? Disabil Rehabil 2001;23:706-21.

9 Durie MH. Whaiora-Maori health

development. Oxford: Oxford University Press, 1998.

10 Kingi Te Kani, Durie MH. Hua Oranga: a Maori measure of mental health outcome. Palmerston North: Massey University, School of Maori Studies, 2000.

\section{High reliability organizational change for hospitals: translating tenets for medical professionals}

\section{J Shapiro, G D Jay}

Health care will continue to struggle to improve patient safety until the medical industry and hospital leaders understand that the tenets of high reliability organizations can be translated for physicians and nurses.

$\mathrm{D}$ espite the significantly increased attention to patient safety, it remains unclear what role healthcare professionals-both individually and collectively - should play in supporting organizational change. Concurrently, the model of error is shifting away from the individual towards the system to search for solutions, which has left a void in the area of human performance. Medical industry leaders at the chief executive level have a vision which focuses on information systems and streamlined system improvements. These tangible technological solutions, such as Computerized Physician Order Entry (CPOE), share specificity to fix an identifiable problem, making them comfortable targets for patient safety initiatives. While this approach will yield positive results, it is important to remember that up to $75 \%$ of information technology solutions are likely to fail. ${ }^{1}$ Complementary behavioral solutions such as teamwork should therefore be recognized for their potential to mitigate error and increase system resilience. ${ }^{23}$ These human performance interventions, because of their broad adaptability, may have the potential to produce a greater reduction in adverse events.
Reluctance to adopt lessons learned in other industries, some of them in the form of qualitative data, is partly what fuels the controversy between the evidence-based camps and healthcare safety experts who feel there is an urgency to act. ${ }^{45}$ For example, the Institute of Medicine (IOM) recommenagement (CRM) and proven training methods (simulation) and to train teams in the units where they actually function (IOM principle 3 ) has received limited application in large healthcare systems. Without such training it is highly unlikely that loosely organized working groups will ever make the transition to superior performing teams. ${ }^{7}$ As in aviation, the human contribution to adverse dation 8.1 to adopt crew resource man- events in medicine is significant ${ }^{89}$ and should be a priority for any comprehensive error reduction strategy. Conversely, human variability should be viewed as a defence barrier to prevent error if individuals and teams are properly trained to support the tenets of a high reliability organization (HRO).

HROs embrace (1) a preoccupation with failure avoidance, (2) a reluctance to simplify interpretations, (3) sensitivity to operations, (4) commitment to resilience, and (5) deference to expertise. ${ }^{10}$ The tenets of an HRO have not been translated into healthcare industry terms to enable caregivers to initiate the cultural changes necessary to assist healthcare organizations function like HROs. We believe these tenets need to be distilled for application at the point of care delivery - the physician, nurse, and patient relationship. We also believe that (1) attitude change, (2) metacognitive skills, (3) system based practice, (4) leadership and teamwork, and (5) emotional intelligence and advocacy and assertion are the respective caregiver instruments which would help to drive the healthcare industry towards a high reliability organizational change (table 1 ).

A preoccupation with failure builds on the primum non nocere which every physician and nurse is familiar with and generally accepts. First "do no harm" is ever present in the lexicon of care providers and is very much in keeping with a preoccupation of failure. Unfortunately, some care providers have the illusion
Table 1 Relationship between high reliability organization (HRO) tenets and individual competencies

\begin{tabular}{ll}
\hline HRO tenet & Corresponding behavior of care provider \\
\hline Preoccupation with failure avoidance & Attitude \\
Reluctance to simplify interpretation & Metacognitive skills \\
Sensitivity to operations & Systems based practices \\
Commitment to resilience & Leadership and teamwork skills \\
Deference to expertise & Emotional intelligence; advocacy and assertion \\
\hline
\end{tabular}


that we have accomplished this hypervigilance but, in reality, we have actually suppressed this tenet because it does not seem acceptable. An attitudinal change required to move forward is already underway with anonymous medical error reporting systems, more open discussion regarding error, and new requirements for error disclosure. In addition, care providers must internalize teamwork concepts consciously to cross monitor the actions of other providers, expand their responsibility beyond their individual tasks, and be accountable for the broader concern of safe delivery of patient care. While system change is the new mantra for medical error reduction, individual practitioners need to remain accountable for specific types of errors such as cognitive error or procedural competency, but it is imperative that these frontline caregivers be supported by a team structure to make them successful in a complex system.

Metacognitive skills are learnable skills which, when coupled with case based learning, provide experiential learning which will help physicians and nurses to avoid numerous human biases known to create and perpetuate chains of error. ${ }^{11}$ Physicians in training are instructed to arrive at a diagnosis which fits the available data without an understanding of how cognitive biases affect their decision making. Medical training needs a formalized structure for teaching cognitive error recognition and forcing strategies to prevent diagnostic and treatment errors. Even experienced physicians and nurses who appreciate the benefits of bias awareness and the hypervigilance necessary to prevent error chains can benefit from a more comprehensive understanding of their cognitive processes.

A sensitivity to operation would be manifested by clinical treatment guidelines and judicial use of computerized information services which provide a shared exchange of clinical information for all caregivers on a team. This extends to ergonomic redesign of clinical environments to foster interchange. This is also true for other technological innovations, including the use of portable computer systems which enable clinicians to document and review patient charting in the highly mobile environment in today's hospitals. Existing policies and procedures attempt to define system based practices but most are too narrowly defined, overcomplicated, and not consistently applied. Systems based practice has only recently become an Accreditation Council of Graduate Medical Education (ACGME) competency requirement for US residency programs, a recognition that graduate physician training must encompass a broader perspective. However, the true meaning of system based practice remains elusive, and it is difficult to identify which improvement efforts require prioritization. Technically competent care providers cannot be completely successful in delivering safe and efficient care without a better working knowledge of the complex system in which they practice.

A commitment to resilience is evident in nursing practice by the recent debate on mandatory overtime. Both nurses and physicians are committed to never abandoning a patient as a principle, and are sensitive to its perceived occurrence. This value is truly a commitment to resilience and is translatable across all caregivers as emotional intelligence ${ }^{12} 13$ which is formed in part from leadership and teamwork. Deference to expertise is intertwined in these skills, which is best manifested as advocacy and assertion on the level of the individual caregiver. Physicians, in particular, have been trained as individuals and practice in that way. The physician's value system prefers not to admit mistakes and to appear both erudite and correct most of the time. However, the increasing burden placed upon healthcare systems, coupled with the explosion of new information for which physicians and nurses are responsible, should override these concerns. Caregivers, regardless of rank, should advocate and assert corrective positions and actions when error is observed or anticipated. More importantly, the receiver of such a challenge should defer to this momentary expertise and do so in an emotionally intelligent way. These skills are also learnable in the context of training for teamwork and leadership. We believe that the end user HRO trait of commitment to resilience and deference to expertise can be learned in this way.

Health care will continue to struggle to improve patient safety until the medical industry and hospital leaders understand that the tenets of HROs can be translated for physicians and nurses. Curricula need to be developed and provided in a manner which serves as an educational foundation for individual responsibility and accountability to other care providers. Specific interventions such as improved information technology have their place in improving patient safety, but there needs to be a more balanced portfolio of solutions which will include training to improve human performance. At the same time, physicians and nurses must also understand that their efforts are needed to make cultural change possible. Further exploration and research is needed to clarify the interplay between the tenets of HROs and the individual caregiver-patient relationship.

Qual Saf Health Care 2003;12:238-239

Authors' affiliations

M J Shapiro, G D Jay, Center for Safety in Emergency Care, Brown Medical School/Rhode Island Hospital, Providence, RI 02903, USA

Correspondence to: Dr M J Shapiro, Center for Safety in Emergency Care, Brown Medical School/Rhode Island Hospital, Providence, RI 02903, USA; mshapiro@lifespan.org

\section{REFERENCES}

1 Willcocks L, Lester S. Evaluating the feasibility of information technology research. Discussion paper DDP 93/1. Oxford: Oxford Institute of Information Management, 1993.

2 Morey JC, Simon R, Jay GD, et al. Error reduction and performance improvement in the emergency department through formal teamwork training: evaluation of results of the MedTeams Project. Health Serv Res 2002;37: 1553-81.

3 Morey JC, Simon R, Jay G, et al. A transition from aviation crew resource management to hospital emergency departments: The MedTeams story. In Proceedings of the Twelfth International Symposium on Aviation Psychology. Columbus, $\mathrm{OH}$ : The Aviation Psychology Laboratory of the Ohio State University, 2003: 826-32.

4 Leape LL, Berwick DM, Bates DW. What practices will most improve patient safety? Evidence-based medicine meets patient safety. JAMA 2002;288:501-7.

5 Shojania K, Duncan B, McDonald K, et al, eds. Making health care safer: a critical analysis of patient safety practices. Evidence Report/Technology Assessment No. 43. AHRQ Publication 01-E058. Rockville, MD: Agency for Healthcare Research and Quality (AHRQ), 2001

6 Kohn LT, Corrigan JM, Donaldson MS, eds. To err is human: building a safer care system. Washington, DC: National Academy Press, 1999.

7 Fried BJ, Topping S, Rundall TG. Groups and teams in health services organizations. In: Shortell SM, Kaluzny AD, eds. Health care management: organization design and behavior. 4th ed. Albany, NY: Delmar, 2000: 154-90.

8 Kumar V, Barcellos WA, Mehta MP, et al. An analysis of critical incidents in a teaching department for quality assurance: a survey of mishaps during anaesthesia. Anesthesia 1988;43:879-83.

9 Chopra V, Engbers FHM, Geerts M, et al. The Leiden anaesthesia simulator. Br J Anaesth 1994;73:287-92.

10 Rochlin GI. Defining "high reliability" organizations in practice: a toxonomic prologue. In Roberts KH, ed. New challenges to understanding organizations. New York: Macmillan, 1993: 11-32.

11 Croskerry P. Achieving quality in clinical decision making: cognitive strategies and detection of bias. Acad Emerg Med 2002;9: 1 184-204

12 Goleman D. Working with emotional intelligence. New York: Bantam, 1998.

13 Goleman D, Boyatzis R, McKee A. Primal leadership: realizing the power of emotional intelligence. Boston: Harvard Business School Publishing, 2002 
"No fault" compensation

\section{Compensation as a duty of care: the case for "no fault"}

\section{Vincent}

An optimal compensation system should compensate injuries when they occur, but also reduce errors and harm. The tort system used in most countries is increasingly anachronistic and an obstacle to progress on patient safety. A "no fault" system of compensation such as that used in New Zealand may result in better quality of care.

$\mathrm{R}$ trospective medical record reviews suggest that $4-16 \%$ of hospitalised patients suffer harm, which is judged preventable in about half of cases. In the study by Davis et $a l^{1}$ published in this issue of QSHC, 5.2\% of admissions in New Zealand led to a preventable inhospital event, a similar rate to that in the UK and within the broad range of other studies. Clearly these results are important for New Zealand health care, but they also have a special significance because of New Zealand's "no fault" compensation system. To understand this it is necessary briefly to consider the basis and justification for different approaches to compensation for medical injury.

In most countries compensation for medical injury is based on the tort system or other "fault based" models. The claimant-the injured patientmust take legal action to prove duty of care, injury, causation, and negligence. In a "no fault" compensation system an expert panel will assess whether the injury has indeed been caused by health care, but the patient does not have to go to court and does not have to prove negligence in order to be eligible for compensation. Most "no fault" systems do not compensate all injuries from health care. For instance, the New Zealand system compensates for injuries caused by medical error and rare mishaps, but generally not for injuries deemed not to result from error.

The tort system, however, is not simply a system of compensation but is also intended to emphasise accountability of individuals and institutions and to be a deterrent to substandard care. ${ }^{2}$ Simply put, the likelihood of being sued is supposed to inject a certain caution into clinical practice and decision making which is supposed to improve patient care. If this were so, one might think that countries operating tort systems would have a lower level of adverse events. However, the findings of Davis and colleagues, while not a direct test of the impact of tort, suggest at the very least that such an effect is fairly marginal-if it exists at all.

Tort systems may have had some positive effects. The rise in litigation, and reflection on its causes, was certainly one powerful driver towards assessing the full extent of harm to patients. Arguably, the threat of litigation has promoted better communication with patients and more collaborative decision making. In Britain the NHS Litigation Authority requires hospitals to appoint risk managers with some responsibility for reducing risk as well as managing claims. There are, however, many negative consequences to set against these positive influences.

With the rise of patient safety and systems thinking about the causes of adverse events, the tort system is looking increasingly anachronistic and an obstacle to progress on patient safety. The system has been criticised as costly, slow, inequitable in various respects, and blame orientated. It can be traumatic for those involved-patients and professionals alike-inducing much bitterness on both sides. The system is inherently adversarial and, although much of the trauma can be reduced by sympathetic and effective lawyers on both sides, patients still have to fight for compensation at a time when they really need to be looked after. Reforms being considered in Britain include fixed tariffs for specific injuries, alternative dispute resolution, structured payouts instead of large "one off" lump sums, as well as "no fault" systems. ${ }^{4}$

Tort is built, in practice at least, on the notion of individual fault. Typically, specific lapses in the standard of care provided by individuals are identified as the grounds for compensation. While not denying that clinicians do make specific errors, recent approaches to understanding adverse events emphasise that there is usually a chain of events leading to an adverse outcome, each of which may be influenced by a wide range of contributory factors. ${ }^{5}$ There is therefore a tension-in fact, a fundamental incompatibility-between a judicially orientated enquiry and the systemic investigations required for improving safety. Furthermore, fears of litigation are a frequently voiced obstacle to open reporting of errors and adverse events. While some clinicians' fears can be offset by confidential or anonymous reporting, in a tort system there is always a trade off between the interests of patients and patient safety and the interests of clinicians and healthcare organisations.

An optimal system must act to reduce errors and harm and yet also compensate injuries once they occur. Studdert and Brennan ${ }^{3}$ argue that such a system should have five broad characteristics:

- the programme should encourage healthcare professionals to report errors;

- it should send strong quality improvement signals with financial incentives for safety and quality;

- it must include mechanisms to deal with the small number of rogue or reckless clinicians who harm patients;

- the compensation programme should act to reinforce rather than undermine the honesty and openness of the clinician-patient relationship; and

- where appropriate, patients should be compensated in a manner that is speedy, equitable, affordable, and predictable.

Studdert and Brennan consider that a "no fault" system can achieve all five goals, and argue that such systems should now be piloted in the United States.

Several "no fault" compensation systems with different characteristics operate internationally in Denmark, Sweden, Finland, and New Zealand. The Swedish approach, for instance, has proved to be efficient and affordable, although backed by a strong social security system. Physicians in Sweden appear to regard assisting with compensation claims as a continuation of the duty of care and as a natural part of their responsibility to their patients. Studies by Brennan and colleagues suggest that implementing the Swedish system of compensation, which employs a criterion of avoidability of injury as grounds for compensation, would not lead to greatly increased overall costs in the United States, but would compensate 
many more injured patients. Incentives for enhancing quality and safety of care can be built into "no fault" systems in several ways, usually in the form of "enterprise liability" by which a hospital or other healthcare organisation becomes liable for the costs of compensation, rather than individual clinicians. In addition to providing incentives to safe care, this approach is also consistent with a systems approach to the understanding and prevention of adverse events.

"the idea that [the tort system] acts as an effective deterrent is now bankrupt" $^{\prime \prime}$

While the tort system can still be defended in some respects, and might be more acceptable in some countries than others, the idea that it acts as an effective deterrent is now bankrupt. As Davis and colleagues suggest, we now need to look more directly at the operation of "no fault" systems, both in terms of compensation arrangements and their impact on quality of care. There is, for instance, an assumption that "no fault" systems encourage reporting of errors but there is little evidence to support this view. The most important criterion for assessment of any compensation system should be its impact on injured patients and their families, not just in providing appropriate financial recompense where necessary but in ensuring that explanations, apologies, and long term support and care are regarded as the expectation rather than the exception. ${ }^{6}$ Compensation would ideally be a gesture of reconciliation and an acknowledgement that a healthcare organisation has a special duty of care to those it has harmed.

Qual Saf Health Care 2003;12:240-241

\section{Author's affiliation}

C Vincent, Smith \& Nephew Foundation Professor of Clinical Safety Research, Department of Surgical Oncology and Technology, Imperial College School of Science, Technology and Medicine, St Mary's Hospital Campus, London W2 1NY, UK. c.vincent@imperial.ac.uk

\section{REFERENCES}

1 Davis $\mathbf{P}$, Lay-Yee R, Briant R, et al. Preventable in-hospital medical injury under the "no fault" system in New Zealand. Qua Saf Health Care 2003;12:251-6.

2 Fenn P. Compensation for medical injury: a review of policy options. In: Vincent CA, Ennis M, Audley RJ, eds. Medical accidents. Oxford: Oxford University Press, 1993: 198-208.

3 Studdert DM, Brennan TA. No-fault compensation for medical injuries: the prospect for error prevention. JAMA 2001;286:217-23.

4 Gaine WJ. No-fault compensation systems. BM 2003;326:997-8.

5 Vincent $C$. Understanding and responding to adverse events. N EnglJ Med 2003;348:1051-6.

6 Vincent CA. Caring for patients harmed by treatment. In: Vincent CA, ed. Clinical risk management. Enhancing patient safety. London: BMJ Publications, 2001: 461-79.

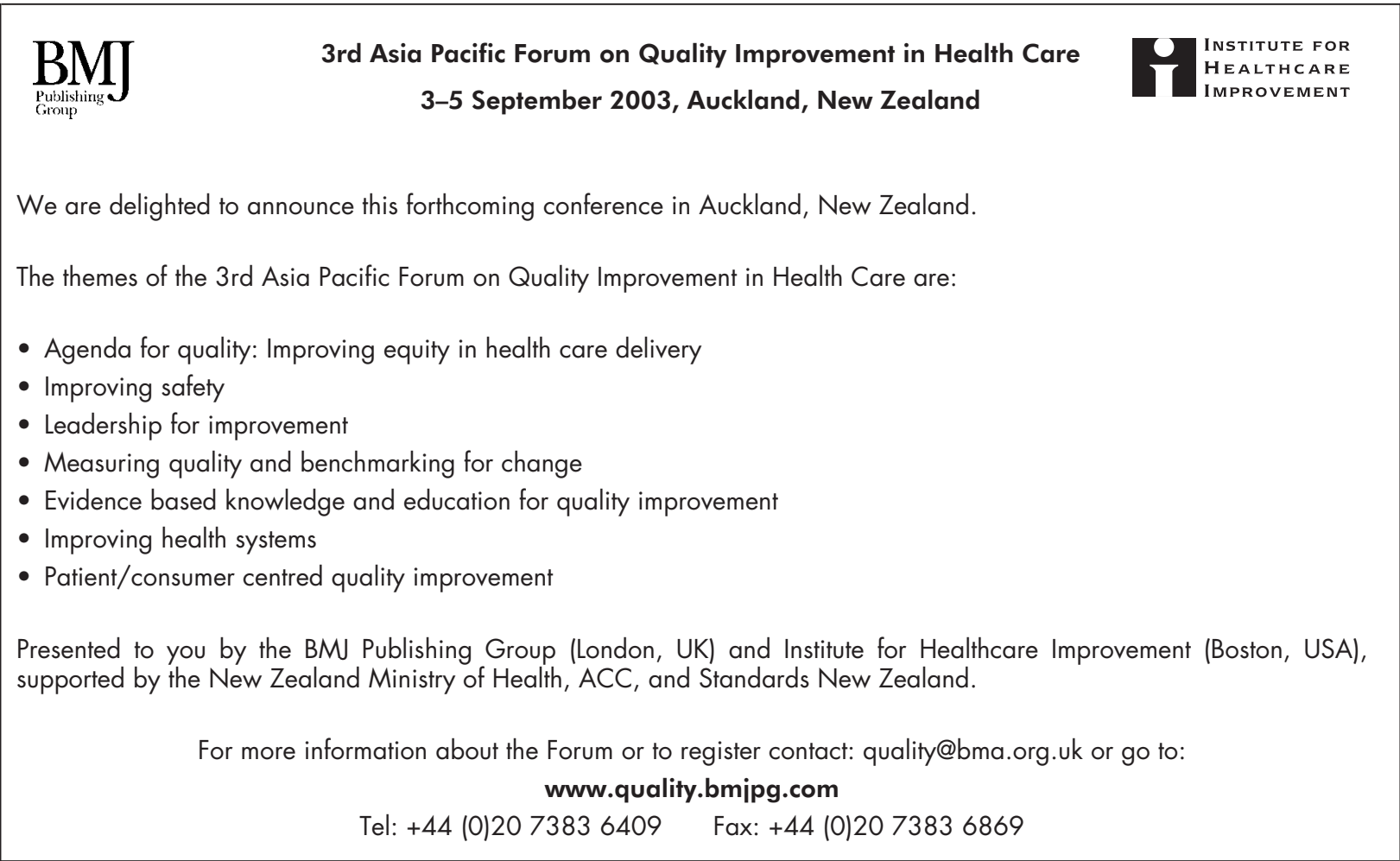

